\title{
Antenatal and intrapartum fetal surveillance in patients with oligohydramnios in a tertiary hospital
}

\author{
Ratnaboli Bhattacharya*, Akshaya S.
}

Department of Obstetrics and Gynaecology, Kasturba Hospital, Delhi, India

Received: 05 July 2016

Revised: 11 July 2016

Accepted: 15 July 2016

\section{*Correspondence:}

Dr. Ratnaboli Bhattacharya,

E-mail: bhattacharya.ratnaboli@gmail.com

Copyright: ( ) the author(s), publisher and licensee Medip Academy. This is an open-access article distributed under the terms of the Creative Commons Attribution Non-Commercial License, which permits unrestricted non-commercial use, distribution, and reproduction in any medium, provided the original work is properly cited.

\begin{abstract}
Background: The evaluation of amniotic fluid is an important index for the early detection and follow-up of fetal pathology during pregnancy. The objective of the study is to know the nature of Doppler in study (AFI $\leq 5)$ and control group (AFI $\geq 5$ ) and the relationship of AFI with nature of CTG in both groups.

Methods: 50 singleton live pregnancies between 34-40 weeks gestation with well-established dates with AFI 5 or less for the study group. 50 singleton live pregnancies between 34-40 weeks gestation with well-established dates with AFI more than 5 were selected for the control group. Ultrasound examination was done for all women whenever they visited the hospital at/after 34 weeks of gestation. AFI was obtained sonographically. Antenatal fetal surveillance using Doppler, NST tracings and intrapartum fetal surveillance using CTG was done in all patients.

Results: $62(62 \%)$ patients in the study group (AFI $\leq 5)$ were found to have deranged Doppler values in contrast to just $30(30 \%)$ patients in the control group (AFI >5). An inverse relationship was found between the amount of amniotic fluid and the number of patients having abnormal Doppler in the study group. Suspicious or pathological CTG was more common in study group (67\%) than the control group (22\%).

Conclusions: Oligohydramnios has the most consistent association with IUGR. Severe oligohydramnios have more probabilities of having abnormal Doppler due to uteroplacental insufficiency. During intrapartum fetal assessment, suspicious or pathological CTG was more common in patients with oligohydramnios due fetal hypoxia during uterine contractions, cord compression and head compression. Hence patients with oligohydramnios should be put on regular antenatal surveillance to reduce the fetal complications and to improve the labour outcome.
\end{abstract}

Keywords: Oligohydramnios, Doppler, CTG, NST

\section{INTRODUCTION}

The evaluation of amniotic fluid is an important index for the early detection and follow-up of fetal pathology during pregnancy. Amniotic fluid index (AFI) of $\leq 5$ defines oligohydramnios as originally described by Phelan et al. ${ }^{1}$

Amniotic fluid is produced by fetal urine and fetal lung fluid. The two primary routes of amniotic fluid removal are fetal swallowing and absorption into fetal blood perfusing the fetal surface of the placenta and membranes. Fetal disorders that affect any of these processes will affect the amniotic fluid volume. Amniotic fluid volume increases from $25 \mathrm{ml}$ at 10 weeks of gestation to about $400 \mathrm{ml}$ at 20 weeks, and a peak of 1 litre at 34-36 weeks to decrease in the late third trimester with a mean of $800 \mathrm{ml}$ at 40 weeks of gestation and declines further to $400 \mathrm{ml}$ at 42 weeks. ${ }^{2,3}$

The fetal complications may include cord compression, musculoskeletal abnormalities such as facial distortion and clubfoot, pulmonary hypoplasia, potters syndrome and intrauterine growth restriction. ${ }^{2}$ 
Some authors think that decreased AFV is a predictor of poor fetal tolerance of labour and is associated with increased risk in abnormal heart rate, caesarean section and meconium stained amniotic fluid. There is also increased risk of Apgar score $<7$ in these cases. ${ }^{4-6}$

The intention of this study is to know the nature of Doppler in study and control group and the relationship of AFI with nature of CTG in both groups.

\section{METHODS}

A prospective cohort study was conducted in the Department of Obstetrics and Gynaecology, Kasturba Hospital from March 2013 to March 2014. The study was conducted after ethical clearance from the institutional ethical committee. 50 singleton live pregnancies between 34-40 weeks gestation with well-established dates with AFI 5 or less were selected for the study group. 50 singleton live pregnancies between 34-40 weeks gestation with well-established dates with AFI more than 5 for the control group. Those who remembered the date of their last menstrual period correctly with previous regular cycles and/or had corresponding first trimester ultrasound were taken for the study. Patients with multiple pregnancies, with IUD at the time of diagnosis or with previous history of uterine surgeries which preclude trial of labour were excluded from the study. Apart from a detailed history and examination, Ultrasound examination was done for all women whenever they visited the hospital at/after 34 weeks of gestation. Fetal maturity, biometry and morphology scan, fetal presentation and placental localization was done. AFI was obtained sonographically. If the AFI was less than or equal to $5 \mathrm{~cm}$, the four quadrant evaluation was performed three times and the values were averaged.

All the women underwent Doppler studies and biophysical scoring. Those with deranged values were repeated weekly and those with normal values were repeated every 15 days until pregnancy termination. Parameters studied were S/D ratio and RI and PI off et al umbilical artery and middle cerebral artery. Biophysical scoring included the following parameters-fetal breathing movements, fetal movements, fetal tone, amniotic fluid and NST. NST tracings were taken for all the women included in the study. Patients with abnormal Doppler studies and biophysical scoring had NST done on alternate days while those with normal values were done weekly till pregnancy was terminated.

\section{Statistical analysis}

Data was entered in a database file on SPSS 14 and analysed using the same software. Data was compared using Chi-square or Fischer's test where appropriate and continuous variables were analyzed with student's t-test. A p-value of $<0.05$ or an odds ratio (OR) with $95 \%$ confidence interval (CI) not inclusive of the unity was considered significant.

\section{RESULTS}

The patients were thus divided into two groups according to AFI: selected study group was: patients with $\mathrm{AFI} \leq 5$, control group: patients with AFI $>5$.

In our study majority of the patients had gravidity between 2 and 3 in both study and control group. The mean age of study group (AFI $\leq 5$ ) was $24.21 \pm 2.16$ years and control group was $24.25 \pm 2.92$ years. The two groups were comparable on the basis of age and gravidity. The mean AFI of study group was $3.605 \pm 1.14 \mathrm{~cm}$ and control group was $12.001 \pm 3.52 \mathrm{~cm}$.

Table 1: Distribution of patients with relation to nature of Doppler in study group (AFI $\leq 5)$.

\begin{tabular}{|llllll|}
\hline AFI & $\begin{array}{l}\text { No of } \\
\text { range(cm) } \\
\text { patients }\end{array}$ & \multicolumn{2}{c|}{$\begin{array}{l}\text { Abnormal } \\
\text { Doppler }\end{array}$} & $\begin{array}{l}\text { Normal } \\
\text { Doppler }\end{array}$ \\
& Value & $\begin{array}{l}\% \\
\text { share }\end{array}$ & Value & $\begin{array}{l}\% \\
\text { share }\end{array}$ \\
\hline $1-2$ & 15 & 14 & $93 \%$ & 1 & $7 \%$ \\
\hline $2.1-3$ & 11 & 10 & $91 \%$ & 1 & $9 \%$ \\
\hline $3.1-4$ & 28 & 19 & $68 \%$ & 9 & $32 \%$ \\
\hline $4.1-5$ & 46 & 19 & $41 \%$ & 27 & $59 \%$ \\
\hline Total & 100 & 62 & $62 \%$ & 38 & $38 \%$ \\
\hline
\end{tabular}

Out of the $15(15 \%)$ patients having AFI $1-2 \mathrm{~cm}, 14$ (93\%) patients had abnormal Doppler and $1(7 \%)$ patient had normal Doppler. Among the 11 (11\%) patients having AFI between 2.1-3 cm, 10 (91\%) patients had abnormal Doppler and $1(9 \%)$ patient had normal Doppler. 28 (28\%) patients had AFI between 3.1-4 cm$19(68 \%)$ patients of them had abnormal Doppler and 9 (32\%) patients had normal Doppler. Amidst the 46 (46\%) patients having AFI $4.1-5 \mathrm{~cm}, 19(41 \%)$ patients had abnormal Doppler, 27 (59\%) patients had normal Doppler. This difference was statistically significant $(\mathrm{p}=0.00)$.

Table 2: Distribution of patients with relation to nature of Doppler in control group (AFI >5).

\begin{tabular}{|c|c|c|c|c|c|}
\hline \multirow{2}{*}{$\begin{array}{l}\text { AFI } \\
\text { range } \\
(\mathrm{cm})\end{array}$} & \multirow{2}{*}{$\begin{array}{l}\text { No of } \\
\text { patients }\end{array}$} & \multicolumn{2}{|c|}{$\begin{array}{l}\text { Abnormal } \\
\text { Doppler }\end{array}$} & \multicolumn{2}{|c|}{$\begin{array}{l}\text { Normal } \\
\text { Doppler }\end{array}$} \\
\hline & & Value & $\begin{array}{l}\% \\
\text { share }\end{array}$ & Value & $\begin{array}{l}\% \\
\text { share }\end{array}$ \\
\hline $5.1-10$ & 30 & 18 & $60 \%$ & 12 & $40 \%$ \\
\hline $10.1-15$ & 53 & 7 & $13 \%$ & 46 & $87 \%$ \\
\hline $15.1-20$ & 17 & 5 & $29 \%$ & 12 & $71 \%$ \\
\hline Total & 100 & 30 & $30 \%$ & 70 & $70 \%$ \\
\hline
\end{tabular}

$30(30 \%)$ patients had AFI ranges 5.1-10 cm. Among them $18(60 \%)$ patients had abnormal Doppler and 12 (40\%) patients had normal Doppler. This difference was statistically significant $(\mathrm{p}=0.00)$. Out of $53(53 \%)$ patients having AFI between 10.1-15 cm, 7 (13\%) patients had abnormal Doppler and $46(87 \%)$ patients had normal Doppler. 17 (17\%) patients had AFI between 15.1-20 cm- 
$5(29 \%)$ patients of them had abnormal Doppler and 12 (71\%) patients had normal Doppler.

In the study group (AFI $\leq 5)$, normal CTG was found only in $33(33 \%)$ patients. $46(46 \%)$ patients had suspicious CTG tracings and $21(21 \%)$ patients had pathological CTG. In contrast, $78(78 \%)$ patients in the control group (AFI>5) had normal traces on CTG, 12 (12\%) patients had suspicious traces and only $10(10 \%)$ patients had pathological CTG. This difference was found to be highly statistically significant $(\mathrm{p}=0.00)$.

Table 3: Relationship of AFI with the nature of CTG in both the groups.

\begin{tabular}{|lllll|}
\hline \multirow{2}{*}{$\begin{array}{l}\text { Nature of } \\
\text { CTG }\end{array}$} & \multicolumn{2}{l|}{$\begin{array}{l}\text { AFI } \leq 5 \\
\text { (study group) }\end{array}$} & \multicolumn{2}{l|}{$\begin{array}{l}\text { AFI }>5 \\
\text { (control group) }\end{array}$} \\
\cline { 2 - 5 } & Value & \%Share & Value & \%Share \\
\hline Normal & 33 & $33 \%$ & 78 & $78 \%$ \\
\hline Suspicious & 46 & $46 \%$ & 12 & $12 \%$ \\
\hline Pathological & 21 & $21 \%$ & 10 & $10 \%$ \\
\hline Total & 100 & $100 \%$ & 100 & $100 \%$ \\
\hline
\end{tabular}

\section{DISCUSSION}

In the present study, mean age of study group (AFI $\leq 5$ ) was $24.21 \pm 2.16$ years and control group was $24.25 \pm 2.92$ years reflecting the child bearing age of most the women which matches with study of Chauhan $P$ et al $(23.6 \pm 6.5$ years). ${ }^{7}$ The mean AFI in the study group (AFI=5) was $3.605 \pm 1.1490 \mathrm{~cm}$. These figures matched with those found by Sadovsky Y et al (mean AFI was $2.9 \mathrm{~cm}$ ). ${ }^{8}$

The research found that $62(62 \%)$ patients in the study group $(\mathrm{AFI} \leq 5)$ were found to have deranged Doppler values in contrast to just $30(30 \%)$ patients in the control group (AFI >5). Normal Doppler values were found in 38 $(38 \%)$ patients in the study group and $70(70 \%)$ patients in the control group. Deranged Doppler readings found were mainly-altered S/D ratios of umbilical artery and middle cerebral artery, decreased diastolic flow, absent diastolic flow and reverse diastolic flow in the umbilical artery. The difference between the two groups was highly significant $(\mathrm{p}=0.00)$ (Table 1,2$)$.

An inverse relationship was found between the amount of amniotic fluid and the number of patients having abnormal Doppler in the study group-lower the AFI, more was the number of patients having abnormal Doppler. The group with AFI 1-2 cm had 93\% of patients with abnormal Doppler while in the group having AFI $4-5 \mathrm{~cm}$, only $41 \%$ patients had abnormal Doppler. The difference was statistically significant $(\mathrm{p}=0.00)$ (Table 1 , $2)$.

In the control group (AFI >5), $18(60 \%)$ patients with AFI $5.1-10 \mathrm{~cm}$ had abnormal Doppler readings as compared to $12(40 \%)$ patients with normal Doppler readings. On the other hand, $12(17.14 \%)$ patients with
AFI 10.1-20 cm had abnormal Doppler reading, whereas $60(82.86 \%)$ patients had normal Doppler values. Thus it was found that if AFI $>10$, fetus is likely to be healthy (Table 1, 2).

Oligohydramnios has the most consistent association with IUGR. The mechanism is uteroplacental insufficiency which explains the genesis of both fetal growth restriction and decreased liquor. This is the reason why abnormal Doppler values are more common in these patients. This also explains the fact that patients with severe oligohydramnios have more probabilities of having abnormal Doppler (Table 1, 2).

Figures matched with those found by Carroll et al, who found $61.7 \%$ patients with oligohydramnios had abnormal S/D ratios. ${ }^{9}$ Arora et al also found an association between oligohydramnios and abnormal Doppler velocimetry (Table 1,2$){ }^{10}$

In the study group (AFI $\leq 5)$, normal CTG was found only in $33(33 \%)$ patients. $67(67 \%)$ patients had either suspicious or pathological CTG. In contrast, 78 (78\%) patients in the control group (AFI >5) had normal traces on CTG, $22(22 \%)$ patients had suspicious traces or pathological CTG. This difference was found to be highly statistically significant $(p=0.00)$. This was because fetuses having oligohydramnios are more likely to be compromised and in stress. Fetal hypoxia is more common in these infants. Uterine contractions during labour cause a compromise in the blood flow and cord compression as well as head compression is more likely (Table 3).

Figures were slightly more than those found in other studies, Jandial et al found that $38 \%$ patients with decreased AFI had abnormal fetal heart rates. ${ }^{11}$ Umber et al found FHR decelerations in $48 \%$ patients with AFI $\leq 5$ as compared to $38.8 \%$ patients with AFI $>54$. Chate et al found that $38 \%$ patients with oligohydramnios had nonreactive NST as compared to $30 \%$ patients with normal AFI (Table 3). ${ }^{12}$

In the study the numbers of abnormal FHR tracings were more in comparison to previous studies because all the patients when in labour undergo CTG monitoring and thus more numbers of patients have been picked up because of better intrapartumfetal assessment facilities (Table 3).

\section{CONCLUSION}

Oligohydramnios has the most consistent association with IUGR. Severe oligohydramnios have more probabilities of having abnormal Doppler due to uteroplacental insufficiency. During intrapartumfetal assessment, suspicious or pathological CTG was more common in patients with oligohydramnios due fetal hypoxia during uterine contractions, cord compression and head compression. Once oligohydramnios is detected, patients 
should be put on regular fetal surveillance such as Doppler studies and NST. Timely termination of pregnancy can reduce the fetal complications and improve labour outcome.

Funding: No funding sources

Conflict of interest: None declared

Ethical approval: The study was approved by the Institutional Ethics Committee

\section{REFERENCES}

1. Phelan JP, Smith CV, Small M. Amniotic fluid volume assessment with four quadrant technique at 36-42 weeks of gestation. J Repod Med. 1987;32:540-2.

2. Misra R. Hydramnios and oligohydramnios. In Renu Misra. Ian Donald's Practical Obstetric Problems. $6^{\text {th }}$ edition. BI Publications Pvt. Ltd;2007:364-375.

3. Dutta DC. The placenta and the membranes. Textbook of obstetrics. $6^{\text {th }}$ edition. New Central Book Agency (P) Ltd;2004:37-39.

4. Umber A. Perinatal outcome in pregnancies complicated by isolated oligohydramnios at term. Annals. 2009;15:35-7.

5. Magann EF, Doherty DA, Lutgendorf MA. Peripartum outcomes of high risk pregnancies complicated by oligohydramnios. J Obstet Gynaecol Res. 2010;36(2):268-77.

6. Guin G, Punekar S, Lele P, Khare S. A prospective clinical study of feto-maternal outcome in pregnancies with abnormal liquor volume. J Obstet Gynaecol India. 2011;61(6):652-5

7. Chauhan SP, Hendrix NW. Intrapartum oligohydramnios does not predict adverse peripartum outcome among high risk parturient. Am J Obstet Gynecol. 1997;176(6):1130-6.

8. Sadovsky Y, Christensen MW. Cord containing amniotic fluid pocket-a useful measurement in the management of oligohydramnios. Obstet Gynecol. 1992;80(5):775-7.

9. Carroll BC, Bruner JP. Umbilical artery Doppler as a predictor of perinatal outcome in pregnancies complicated by oligohydramnios. Am J Obstet Gynecol. 1998;178(1):86.

10. Arora D, Desai SK, Sheth PN, Kania P. Significance of umbilical velocimetry in perinatal outcome of growth retarded fetuses. J Obstet Gynecol. 2005;55(2):138.

11. Jandial C, Gupta S, Sharma S, Gupta M. Perinatal outcome after antepartum diagnosis of oligohydramnios at or beyond 34 weeks of gestation. JK Science. 2007;9(4):213-4.

12. Chate P, Khatri M, Hariharan C. Pregnancy outcome after diagnosis of oligohydramnios at term. Int $\mathbf{J}$ Reprod Contracept Obstet Gynecol. 2013;2(1):23-6.

Cite this article as: Bhattacharya $\mathrm{R}$, Akshaya $\mathrm{S}$. Antenatal and intrapartum fetal surveillance in patients with oligohydramnios in a tertiary hospital. Int J Reprod Contracept Obstet Gynecol 2016;5:2511-4. 